\title{
Mecanismos de avaliação institucional do atendimento socioeducativo
}

\author{
Institutional assessment mechanisms of the socio-educational services
}

\author{
Dione Lolis * \\ Sandra da Cruz Perdigão Domiciano **
}

\begin{abstract}
Resumo:
Este artigo apresenta a experiência desenvolvida na disciplina: "Vivência, Observação no CENSE e Síntese", do Curso de Especialização em Gestão de Centros de Socioeducação realizado em 2009/2010, na Universidade Estadual de Londrina - UEL, como parte do programa estadual de capacitação dos servidores e operadores do Sistema de Garantia de Direitos da Criança e do Adolescente. Tem como escopo primordial compartilhar com os leitores algumas reflexões teóricas e empíricas acerca do processo de avaliação de unidades/programas de socioeducação, construídas a partir de vivências pessoais e profissionais. Apresenta como resultado desse processo de síntese uma proposta de instrumento de avaliação institucional do atendimento socioeducativo para as unidades de meio aberto e meio fechado, construída a partir das categorias e indicadores de qualidade propostos no sistema de monitoramento e avaliação do SINASE.
\end{abstract}

Palavras-chave: Avaliação institucional. Instrumento de avaliação. Socioeducação. SINASE.

\begin{abstract}
:
This article presents the experience developed in the discipline: "Experience, Observation and Synthesis in CENSE," through the Specialization in Management Social education Centers conducted in 2009/2010, at State University of Londrina UEL, as part of the State Program for the qualification of workers and operators in the Guarantee System of Rights of children and adolescents. Its main goal is to share with readers some reflections about the theoretical and empirical evaluation process of social education units and programs, constructed from personal and professional experiences. Presents as a result of this synthesis process, a proposal for an instrument of institutional evaluation of the social and educational care for
\end{abstract}

\footnotetext{
*Assistente social, mestrado em Serviço Social pela Pontifícia Universidade Católica de São Paulo e doutorado em Sociologia pela Universidade Estadual Paulista Júlio de Mesquita Filho Atualmente é professora adjunta da Universidade Estadual de Londrina. dionelolis@uel.br

**Assistente Social, Mestre em Serviço Social pela Pontifícia Universidade Católica de São Paul PUC/SP. Docente do Departamento de Serviço Social. sperdigao@uel.br
} 
the units of half open and half closed, built from the categories and quality indicators in the proposed system of monitoring and evaluation of SINASE.

Keywords: Institutional evaluation. Assessment tool. Social education. SINASE.

\section{Introdução}

Atualmente, as instituições de socioeducação se deparam com uma diversidade de funções e desafios a enfrentar. Demandas de naturezas diversas emergem em forte contexto marcado pelo combate à violência, exclusão social e pela necessidade de instrumentalizar e fortalecer o jovem para o exercício da cidadania.

Para tanto, é necessário que as instituições de socioeducação sejam eficientes e eficazes, respondam aos anseios sociais no que tange a reinserção do adolescente que responde à medida socioeducativa e se consolidem em espaços de (re)organização e aprendizagem da cidadania, para que ele possa ter uma convivência social digna, tendo seus direitos respeitados conforme preconiza o Estatuto da Criança e do Adolescente ECA (BRASIL, 2006a).

Neste contexto, é importante considerar a instituição em sua totalidade, ou seja, em sua estrutura física, organizacional, forma de gestão, política que direciona sua ação, bem como, o resultado que produz no contexto da realidade.

Especificamente no que diz respeito às questões que envolvem os adolescentes que respondem às medidas socioeducativas, o Sistema Nacional de Atendimento Sócio Educativo (SINASE) (BRASIL, 2006b), enquanto uma política pública que visa à inclusão social do adolescente mediante o desenvolvimento de ações socioeducativas, tem como premissa a efetivação de uma política que privilegia os direitos humanos e a organização do sistema de atenção ao adolescente nas diferentes esferas de governo.

De acordo com o SINASE, são competências e atribuições dos entes federativos, "monitorar, supervisionar e avaliar o sistema, a política, os programas e as ações afetas ao atendimento do adolescente desde sua inserção no sistema" (BRASIL, 2006b, p. 33).

Nesta perspectiva, a avaliação institucional se apresenta como uma ferramenta de gestão capaz de produzir importantes benefícios para a instituição de socioeducação, fornecendo subsídios para as ações, caso necessário, para seus usuários e a sociedade. 
A avaliação institucional de políticas e programas governamentais vem se destacando e adquirindo relevância para o planejamento, para a (re)formulação de intervenções, para a modernização do sistema de gestão, entre outros, uma vez que ela se constitui em um processo contínuo de acompanhamento da ação institucional visando a implementação e/ou mudanças necessárias que atendam à finalidade proposta pela política norteadora da ação institucional.

De acordo com Moacir Gadotti (2009, p. 1), a preocupação com a avaliação não é recente, assim como a avaliação deixou de ser vista como apenas um "instrumento de controle burocrático e centralização em conflitos com a autonomia. Ela esta sendo institucionalizada como um processo necessário a administração, condição necessária para a melhoria do ensino e da pesquisa e exigência da democratização".

A avaliação, contudo, ainda encontra resistência dos gestores e executores dos serviços, uma vez que em muitas situações ela está permeada pela visão de que se trata de um processo fiscalizador e punitivo.

Para Gadotti (2009, p. 2), “avaliar é um ato que exercemos constantemente no nosso cotidiano [...]. Quando avaliamos processos, atos, coisas, pessoas, instituições, estamos atribuindo valores [...]." O autor diz também que este processo pode ser realizado por meio de um "diálogo construtivo ou ao contrário, transformar a avaliação num momento autoritário e repressivo."(GADOTTI, 2009, p. 2).

Nessa perspectiva, é importante ressaltar que ao estabelecer um processo de avaliação, a definição dos objetivos que se deseja alcançar, o envolvimento e a adesão dos sujeitos que integram os diferentes espaços institucionais são necessários, pois, no processo de avaliação existe uma interação de diferentes variáveis. Gadotti (2009, p. 4) aponta que,

[...] estabelecer uma filosofia que sirva de base para orientar o processo de avaliação é fundamental para o seu êxito. Se não se define essa orientação o processo avaliativo pode se transformar numa atividade rotineira e burocrática sem sentido. É essa teoria de base que definirá tanto os objetivos quanto o planejamento e os métodos a serem utilizados.

Em conformidade com esse entendimento, o SINASE estabelece um sistema de monitoramento e avaliação, o qual é entendido como: 
[...] um conjunto de ações de caráter político estratégico que visa introduzir parâmetros para as entidades e/ou programas de atendimento socioeducativo que executam o atendimento inicial, a internação provisória e as medidas socioeducativas, bem como produzir informações para sua melhoria e a publicização dos dados em âmbito nacional (BRASIL, 2006b, p. 77).

Para tanto, estabelece dois procedimentos complementares, ou seja, o monitoramento e a avaliação. Entre os estudiosos há uma convergência no sentido de se estabelecer uma diferenciação entre esses procedimentos. Conforme Carla Cunha (2006, p. 12),

[...] enquanto o acompanhamento ou monitoramento é uma atividade gerencial interna, realizada durante o período de execução e operação, a avaliação pode ser realizada antes, durante a implementação ou mesmo algum tempo depois, após o programa provocar todo o seu impacto, e com a preocupação centrada no modo, medida e razão dos benefícios advindos.

Nesse sentido, pode-se dizer que o monitoramento e a avaliação são ações complementares, sistemáticas e periódicas. Cunha (2006, p. 12) reforça que:

[...] a avaliação vai além, na medida em que realiza a verificação de que o plano originalmente traçado está efetivamente alcançando as transformações que pretendia, subsidiando a definição de políticas públicas. Mas a avaliação necessita das informações provenientes do monitoramento para realizar o julgamento que lhe cabe, a respeito da eficiência, eficácia e efetividade dos programas.

O SINASE estabeleceu o sistema de monitoramento e avaliação do fluxo de atendimento socioeducativo por meio do Sistema de Informação para a Infância e Adolescência (SIPIA) e do Sistema de Controle Informacional de Adolescentes em Conflito com a Lei (INFOINFRA) (BRASIL, 2006b). E, ainda, o monitoramento e a avaliação da qualidade dos programas de atendimento socioeducativo a partir do estabelecimento de categorias e indicadores de avaliação para as medidas socioeducativas em meio aberto e em meio fechado, com o objetivo de:

1) Acompanhar as diferentes modalidades de atendimento ao adolescente a partir de critérios e indicadores de qualidade dos serviços prestados, tendo por base a garantia dos direitos; 
2) Desenhar e consensuar padrões de qualidade do atendimento acompanhando continuamente e com regularidade a eficácia dos projetos desenvolvidos pelos programas de atendimento socioeducativo (BRASIL, 2006b, p. 81).

Vale salientar que ao se estabelecer um sistema de avaliação há que se definir a sua modalidade, se interna, externa, mista ou participativa, bem como sua natureza, formativa ou somativa, assim como os responsáveis pelo processo. De modo geral, as avaliações podem ser conduzidas por especialistas externos ou gestores de programas.

Levando em consideração a importância da avaliação no contexto das políticas e programas governamentais, o Estado do Paraná por intermédio da Secretaria de Estado da Criança e da Juventude (SECJ), em conjunto com a Secretaria Especial dos Direitos Humanos da Presidência da República (SEDH), do Conselho Nacional dos Direitos da Criança (CONANDA), e do Conselho Estadual dos Direitos da Criança e do Adolescente (CEDCA/PR), organizaram o curso de pós-graduação lato sensu, nível de especialização, em "Gestão de Centros de Socioeducação", objetivando a formação de profissionais para a gestão de Centros de Socioeducação (CENSE). ${ }^{1}$

Este curso aconteceu em três regiões do estado, no período de 2009/2010, e contou com participações da Universidade Federal do Paraná (UFPR), Universidade Oeste do Paraná (UNIOESTE) e Universidade Estadual de Londrina (UEL), cada uma atuando em uma dessas regiões. Este último teve a coordenação do Departamento de Serviço Social, por meio do Projeto Integrado de Estudos sobre a Criança e o Adolescente (PROECA).

Participaram do curso os servidores públicos da SECJ, servidores públicos de outras secretarias de Estado ou esferas públicas, conselheiros tutelares e de direitos e funcionários ou dirigentes de organizações não governamentais que atuam no Sistema de Garantia de Direitos da Criança e do Adolescente (SGDCA) (PARANÁ, 2009).

A organização pedagógica do curso contemplou disciplinas teóricas e uma disciplina prática de "Vivência, Observação no CENSE e Síntese", com 75 horas/aula. O eixo norteador desta disciplina consistiu na elaboração e aplicação de instrumento de

\footnotetext{
${ }^{1}$ o Curso teve a duração de 365 horas/aula presenciais e as disciplinas: Fundamentos de gestão; Avaliação institucional; Metodologia de pesquisa; Compreensão histórica e social da violência e o sistema de justiça juvenil; O sistema socioeducativo; Gestão pedagógica do processo socioeducativo; O gestor público no processo socioeducativo; Gestão de recursos públicos; Sistemas de informação e segurança; Vivência/observação no CENSE e síntese e monografia.
} 
avaliação institucional, pautado na Constituição Federal de 1988, no ECA, SINASE e Normativas Internacionais, com vistas ao desenvolvimento de estratégias de aperfeiçoamento e qualificação do trabalho socioeducativo.

Considerando o exposto, este artigo objetiva apresentar o processo de desenvolvimento da disciplina, coordenada pelas autoras/docentes da UEL, e os resultados da experiência de elaboração e aplicação de instrumentos de avaliação institucional do atendimento socioeducativo em Londrina, construído a partir das categorias e indicadores de qualidade dos programas de atendimento socioeducativo para o meio aberto e o meio fechado, propostos no sistema de monitoramento e avaliação do SINASE (BRASIL, 2006b).

\section{Mecanismos de avaliação institucional do atendimento socioeducativo}

O ECA, desde a sua promulgação em 1990, especificava as medidas socioeducativas $^{2}$ e definia o direito material (direitos e obrigações) do ato infracional, regrando o procedimento com o devido processo legal. No entanto, a fase da execução da medida socioeducativa não era tratada na Lei, cabendo aos Tribunais de Justiça e às entidades de atendimento a sua regulamentação. Em 2006, foi editado pelo CONANDA, em conjunto com a SEDH, o SINASE (BRASIL, 2006b), ${ }^{3}$ o qual se encontra em processo de transformação em lei, na intenção de criar um sistema de socioeducação, programas e planos na área.

O debate que resultou na proposição do SINASE foi justamente movido pela preocupação com o que fazer no enfrentamento das situações de violência, que envolvem adolescentes enquanto autores de ato infracional, ou como pessoas que têm seus direitos violados no cumprimento de medidas socioeducativas, além de buscar apresentar uma proposta que articulasse os distintos níveis de governo e corresponsabilizasse a família, a sociedade e o Estado (BRASIL, 2006b, p. 11). Recordando que a doutrina de proteção integral disposta na Constituição de 1988 e no ECA eleva

\footnotetext{
2 São medidas socioeducativas: advertência, obrigação de reparar o dano, prestação de serviços à comunidade, liberdade assistida, semiliberdade e internação.

${ }^{3}$ O SINASE (BRASIL, 2006b) é fruto de uma construção coletiva que envolveu desde 2004 diversas áreas de governo, representantes de entidades e especialistas na área, além de uma série de debates em que participaram os operadores do SGD em encontros regionais que cobriram todo o país.
} 
crianças e adolescentes à condição de sujeitos de direitos, reconhecendo-os como pessoas em desenvolvimento, além de conferir à família, ao Estado e à sociedade o dever de assegurar seus direitos fundamentais de proteção com prioridade absoluta.

Com isso, o SINASE pretende desconstruir o mito da adolescência-problema que existe no país e mostrar esta fase da vida como uma possibilidade de aprendizagem, socialização e desenvolvimento (VOLPI, 2001; SARAIVA, 2002). Desta forma, o Estado e as políticas públicas devem oferecer aos adolescentes possibilidades para a efetivação dos direitos formais.

Nessa direção, a intenção dos elaboradores do SINASE foi definir, como premissa básica, a necessidade de se constituir parâmetros mais objetivos e "procedimentos mais justos que evitem ou limitem a discricionariedade" (BRASIL, 2006b, p. 13), com vistas a subsidiar o CONANDA, buscando reafirmar a diretriz do ECA sobre a natureza pedagógica da medida socioeducativa, propondo a implementação de políticas voltadas ao adolescente que incorreu em ato infracional e a regulamentação da execução dessas medidas. Procura, ainda, compor um documento teórico-operacional para a execução das medidas socioeducativas que discuta a prática pedagógica desenvolvida nas unidades socioeducativas, tendo em vista a falta de orientação pedagógica para a implementação das medidas como para o trabalho nas unidades de internação, depois de verificar que na maioria das regiões do país a sua implementação só ocorre no plano legal.

Algumas das políticas, regras e princípios que tangem a política de atendimento desses adolescentes, previstos no SINASE, além do ECA, fundamentam-se na Constituição Federal de 1988 e nos acordos internacionais sobre direitos humanos dos quais o Brasil é signatário, como: Convenção Internacional Sobre os Direitos da Criança, Regras Mínimas das Nações Unidas para a Administração da Infância e da Juventude e Regras Mínimas das Nações Unidas para a Proteção dos Jovens Privados de Liberdade.

O Projeto de Lei no 1.627, em tramitação desde 2007, que propõe a criação do SINASE, em seu Art 1으, par. 1ํ, o define como um:

Conjunto ordenado de princípios, regras e critérios, de caráter jurídico, político, pedagógico, financeiro e administrativo, que envolvem o processo de apuração de ato infracional e de execução de medida socioeducativa, incluindo-se nele, por adesão, o sistema nos níveis estaduais, distrital e municipais, bem como todos os planos, políticas e programas específicos de atenção ao adolescente em conflito com a lei (BRASIL, 2007). 
Cabendo à União, entre outras competências, formular e coordenar a execução da política nacional de atendimento socioeducativo, elaborar o Plano Nacional de Atendimento Sócio educativo, em parceria com os Estados, o Distrito Federal e os Municípios, bem como, conforme o Art. 3ํㅡ, inciso VII, "instituir e manter processo de avaliação dos Sistemas de Atendimento Sócio educativo, seus planos, entidades e programas" (BRASIL, 2007).

Dentre os princípios previstos no SINASE para a execução de medidas socioeducativas, citamos os seguintes: a incompletude do sistema, (admitindo-se que o atendimento da unidade física é incompleto e que os gestores necessitam atuar em rede, com os sistemas e políticas públicas - de saúde, trabalho, educação etc.), a intersetorialidade, a excepcionalidade e a brevidade.

É importante evocar o art. 106 do ECA, quando enfatiza a prioridade na aplicação das medidas em meio aberto (prestação de serviço à comunidade e liberdade assistida) em detrimento das restritivas de liberdade (semiliberdade e internação em estabelecimento educacional, que somente devem ser adotadas em caráter de excepcionalidade e brevidade). ${ }^{4}$ Essa estratégia visa "reverter a tendência crescente de internação dos adolescentes bem como confrontar a sua eficácia invertida, uma vez que se tem constatado que a elevação do rigor das medidas não tem melhorado substancialmente a inclusão social dos egressos do sistema socioeducativo" (BRASIL, 2006b, p. 14).

Desse modo, a prioridade deve ser dada à municipalização dos programas de meio aberto, articulando-os às políticas intersetoriais locais e a constituição de redes de apoio nas comunidades, e a regionalização dos programas de privação de liberdade, no intuito de garantir o direito à convivência familiar e comunitária dos adolescentes internos e suas especificidades culturais.

Nessa direção, o documento do SINASE indica a necessidade da implementação de uma proposta pedagógica prevista no ECA, capaz de se constituir em ação formadora dos adolescentes que se encontram submetidos ao cumprimento de medidas socioeducativas. Para além da sua natureza sancionatória, recorre ao argumento da

\footnotetext{
4 “Nenhum adolescente será privado de sua liberdade senão em flagrante de ato infracional ou por ordem escrita e fundamentada da autoridade judiciária competente." (BRASIL, 2006a).
} 
natureza sociopedagógica, que se baseia na crença que tem sido assumida e reforçada em diversos discursos sobre socioeducação, de que o fim para a ação socioeducativa é preparar os indivíduos para a vida social, e o fim da socioeducação é formar os indivíduos para o exercício da cidadania, como se lê a seguir:

\begin{abstract}
As medidas socioeducativas possuem em sua concepção básica uma natureza sancionatória, vez que responsabilizam judicialmente os adolescentes, estabelecendo restrições legais e, sobretudo, uma natureza sócio-pedagógica, haja vista que sua execução está condicionada à garantia de direitos e ao desenvolvimento de ações educativas que visem à formação da cidadania. Dessa forma, a sua operacionalização inscreve-se na perspectiva éticopedagógica (BRASIL, 2006b, p. 47).
\end{abstract}

Assim, conforme a análise de Neidson Rodrigues (2001), podemos dizer que a ação socioeducativa constitui-se num processo que tem por objetivo preparar a pessoa em formação (adolescentes) para assumir papéis sociais relacionados à vida coletiva, à reprodução das condições de existência (trabalho), ao comportamento aceitável na vida pública e ao uso adequado e responsável de conhecimentos e habilidades disponíveis no tempo e nos espaços onde a vida dos indivíduos se realiza. O conjunto das ações educativas a serem desempenhadas pelos educadores deve buscar a articulação entre as relações práticas da educação e a necessidade do adolescente à vida política e social, individual e coletiva, dotando os educandos dos instrumentos que lhes são necessários e pertinentes.

Essa ideia está presente no texto do artigo 3을 do ECA, e fundamenta a finalidade maior da socioeducação.

A criança e o adolescente gozam de todos os direitos fundamentais inerentes à pessoa humana, sem prejuízo da proteção integral de que trata esta Lei, assegurando-se-lhes, por lei ou por outros meios, todas as oportunidades e facilidades, a fim de lhes facultar o desenvolvimento físico, mental, moral, espiritual e social, em condições de liberdade e de dignidade (BRASIL, 2006a).

Com base na afirmação de Rodrigues (2001), as ações socioeducativas, devem constituir-se em ações de exercício de cidadania, ${ }^{5}$ e os programas socioeducativos devem

\footnotetext{
${ }^{5}$ Novamente, conforme Rodrigues (2001, p. 238), cidadania pode ser definida a partir de dois aspectos ou ações interdependentes: "à participação lúcida dos indivíduos em todos os aspectos da organização e da condução da vida privada e coletiva"; "à capacidade que estes indivíduos adquirem para operar escolhas". Este exercício da cidadania pressupõe, portanto, a liberdade, a autonomia e a responsabilidade e o dever dos cidadãos de participarem na organização da vida social.
} 
propiciar aos educandos os meios intelectuais e emocionais para que sejam capazes de assumir o pleno uso de suas potencialidades, física, intelectual, moral e espiritual, na condução contínua de sua própria formação, para construir um modo de viver que lhes permita o exercício de sua liberdade, com responsabilidade. Assim a socioeducação é entendida como o processo de formação humana integral e deve ser articulada a partir dos eixos do desenvolvimento físico, mental, moral, espiritual e social.

A partir desses parâmetros, como já mencionamos, o SINASE busca estabelecer um sistema de monitoramento e avaliação dos programas de atendimento socioeducativo. Para isto, define quatro categorias e respectivos indicadores de qualidade a serem avaliados pelos referidos programas em meio aberto e em meio fechado.

Com relação aos direitos humanos, por exemplo, as unidades e/ou programas, de acordo com a modalidade de atendimento deverão garantir o acesso dos adolescentes aos programas públicos e comunitários, como escolarização formal, atividades desportivas, culturais e de lazer internas e externas - com regularidade e freqüência, assistência religiosa, atendimento de saúde na rede pública, inserção em atividades profissionalizantes e inclusão no mercado de trabalho, como vemos a seguir (Quadros 1 e 2).

Quadro 1 - Medidas socioeducativas em meio aberto.

\begin{tabular}{|l|l|}
\hline Categoria 1- Direitos Humanos & Categoria 2- Ambiente físico e infraestrutura \\
\hline - Documentação civil & - Capacidade física \\
- Documentação escolar & - Salubridade \\
- Escolarização & - Banheiros \\
- Profissionalização/ trabalho & - Espaço para atividades em grupo \\
- Esporte & - Espaço para o atendimento individual \\
- Cultura & - Equipamentos \\
- Lazer & - Segurança \\
- Atenção integral à saúde & \\
- Respeito e dignidade; & \\
- Participação em atividades comunitárias & \\
\hline Categoria 3- Atendimento socioeducativo & Categoria 4- Gestão e Recursos Humanos \\
\hline - Atendimento familiar & - Capacidade de gestão \\
- Atendimento jurídico & - Planejamento e Projeto Pedagógico \\
- Atendimento técnico & - Formação e capacitação de recursos humanos \\
- Encaminhamento para a rede de & - Supervisão e apoio de assessorias externas \\
atendimento & - Coleta e registro de dados e informações \\
- Plano Individual de Atendimento (PIA) & - Avaliação \\
\hline
\end{tabular}

Fonte: SINASE (BRASIL, 2006b, p. 81). 
Quadro 2 - Medidas socioeducativas em meio fechado

\begin{tabular}{|l|l|}
\hline Categoria 1- Direitos Humanos & Categoria 2- Ambiente físico e infraestrutura \\
\hline - Alimentação & - Capacidade física \\
- Vestuário & - Salubridade \\
- Higiene pessoal & - Refeitório \\
- Documentação civil & - Dormitório \\
- Documentação escolar & - Banheiros \\
- Escolarização & - Espaço para escolarização \\
- Profissionalização/ trabalho & - Espaço para o atendimento à saúde \\
- Esporte & - Espaço para a prática de esportes, cultura e lazer \\
- Cultura & - Espaço para o atendimento jurídico, social e \\
- Lazer & psicológico \\
- Atenção integral à saúde & - Espaço para a profissionalização \\
- Assistência espiritual & - Espaço para a visita íntima \\
- Respeito e dignidade & - Espaço ecumênico \\
- Direitos sexuais e reprodutivos & - Equipamentos \\
- Direitos políticos & - Segurança \\
\hline Categoria 3- Atendimento socioeducativo & - Parcerias \\
\hline - Atendimento familiar; & - Capacidacia 4- Gestão e Recursos Humanos \\
- Atendimento jurídico; & - Planejamento e Projeto Pedagógico Formação e \\
- Atendimento técnico; & capacitação de recursos humanos \\
- Atendimento ao egresso no caso de & - Plano de cargos e salários \\
internação; & - Supervisão e apoio de assessorias externas \\
- Plano Individual de Atendimento (PIA). & Coleta e registro de dados e informações \\
& Avaliação \\
\hline
\end{tabular}

Fonte: SINASE (BRASIL, 2006b, p. 82).

As estruturas físicas das unidades de atendimento e/ou programas deverão ser orientadas pelo projeto pedagógico e estruturadas de modo a assegurar um ambiente físico e estrutura com capacidade física para o atendimento adequado à execução desse projeto, de acordo com a modalidade de atendimento e a garantia dos direitos fundamentais dos adolescentes. Conforme os parâmetros arquitetônicos normatizados pelo SINASE, as entidades e/ou programas de atendimento deverão assegurar os aspectos físicos a seguir (Quadro 3). 
Quadro 3 - Aspectos físicos a serem considerados nas unidades de atendimento e/ou programas socioeducativos

\begin{tabular}{|c|c|c|c|c|c|}
\hline Aspectos físicos a serem considerados & $\begin{array}{l}\text { Internação } \\
\text { provisória }\end{array}$ & PSC* & LA & Semiliberdade & Internação \\
\hline \multicolumn{6}{|l|}{$\begin{array}{l}\text { Condições adequadas de higiene, limpeza, circulação, } \\
\text { iluminação e segurança }\end{array}$} \\
\hline Espaços adequados para a realização de refeições & & QN & QN & & \\
\hline \multicolumn{6}{|l|}{ Espaço para atendimento técnico individual e em grupo } \\
\hline \multicolumn{6}{|l|}{ Condições adequadas de repouso dos adolescentes } \\
\hline \multicolumn{6}{|l|}{ Salão para atividades coletivas e/ou espaço para estudo } \\
\hline \multicolumn{6}{|l|}{ Espaço para o setor administrativo e/ou técnico } \\
\hline \multicolumn{6}{|l|}{ Espaço e condições adequadas para visita íntima } \\
\hline \multicolumn{6}{|l|}{ Espaço e condições adequadas para visita familiar } \\
\hline \multicolumn{6}{|l|}{ Área para atendimento de saúde/ambulatórios } \\
\hline \multicolumn{6}{|l|}{ Espaço para atividades pedagógicas } \\
\hline \multicolumn{6}{|l|}{$\begin{array}{l}\text { Espaço com salas de aulas apropriadas contando com sala de } \\
\text { professores e local para funcionamento da secretaria e direção } \\
\text { escolar }\end{array}$} \\
\hline \multicolumn{6}{|l|}{$\begin{array}{l}\text { Espaço para a prática de esportes e atividades de lazer e cultura } \\
\text { devidamente equipados e em quantidade suficiente para o } \\
\text { atendimento de todos os adolescentes }\end{array}$} \\
\hline Espaço para a profissionalização & & & & & \\
\hline
\end{tabular}

* Quanto à medida socioeducativa de prestação de serviço à comunidade, os aspectos físicos referem-se ao local de cumprimento da medida.

Fonte: SINASE (BRASIL, 2006b, p. 50).

É imprescindível ainda que as entidades e/ou programas organizem o atendimento de forma a garantir alimentação de qualidade e em quantidades suficientes, vestuários adequados e suficientes, acesso à documentação civil e escolar, e a inserção de adolescentes ameaçados, em sua vida e integridade física, em programas especiais de proteção.

Para o atendimento socioeducativo, o SINASE coloca como imprescindível o acompanhamento técnico dos adolescentes por profissionais que tenham conhecimentos específicos na área de atuação profissional e conhecimento em relação à especificidade do trabalho a ser desenvolvido. A equipe multiprofissional (a internação e internação provisória deve ter, no mínimo, médico, enfermeiro, cirurgião dentista, psicólogo, assistente social, terapeuta ocupacional, auxiliar de enfermagem e auxiliar de consultório dentário) deverá ser capaz de acolher e acompanhar os adolescentes e suas famílias em suas demandas e atender aos funcionários, ter habilidade de acessar a rede de atendimento pública e comunitária para responder às situações de violação, promoção e garantia de direitos. 
Na categoria "gestão e recursos humanos", tanto os programas que executam a internação provisória como as medidas socioeducativas, os profissionais devem ser capacitados para o desempenho das funções previstas, bem como, esse pessoal deve ter acesso ou receber formação e capacitação continuada específica para o trabalho socioeducativo e em serviço, que compreenda: capacitação introdutória, formação continuada, supervisão externa e/ou acompanhamento das unidades e/ou programas. As parcerias e alianças estratégicas também são fundamentais na avaliação desta categoria.

\section{"Vivência, observação no CENSE e síntese"}

Em consonância com o projeto pedagógico do curso de "Gestão de Centros de Socioeducação", a disciplina "Vivência, Observação no CENSE e Síntese" foi estruturada a partir do "Monitoramento e Avaliação do SINASE", com ênfase no tópico "Monitoramento e Avaliação de Qualidade dos Programas de Atendimento Sócio educativo", o qual contempla as categorias e indicadores de avaliação desses programas (Quadro 1 e Quadro 2).

Didaticamente, a organização da disciplina se deu a partir de três momentos: sensibilização/orientação para a atividade de avaliação em campo, vivência e síntese.

\section{1- Sensibilização/orientação para a atividade de avaliação em campo.}

A "Vivência, Observação no CENSE e Síntese", em seu modo operacional, incluiu atividades em sala de aula e visitas às unidades/programas de socioeducação em meio fechado, ${ }^{6}$ no CENSE I (internação provisória), CENSE II (internação) e semiliberdade; e em meio aberto, envolvendo o Projeto Murialdo, ${ }^{7}$ que executava as medidas de liberdade assistida (LA) e de prestação de serviços à comunidade (PSC), bem como a elaboração e a aplicação de instrumento de avaliação.

\footnotetext{
${ }^{6}$ O CENSE I, CENSE II e a Semiliberdade são unidades estaduais que estiveram vinculadas à Secretaria da Criança e da Juventude até o início do ano de 2011, passando depois a ser coordenadas pela Secretaria da Família e Desenvolvimento Social do Estado do Paraná.

${ }^{7}$ O Projeto Murialdo, vinculado à Escola Profissional e Social do Menor de Londrina - EPESMEL, instituição não governamental, executava as medidas de meio aberto (LA e PSC) até 2011. O acompanhamento a essas medidas encontra-se em processo de transferência para a administração direta do poder público municipal.
} 
Para o desenvolvimento destas atividades, o suporte oferecido pelo conjunto das demais disciplinas ministradas ao longo do Curso foi de suma importância, especialmente aquele oferecido pelo conteúdo trabalhado na disciplina "Avaliação Institucional", por propiciar aos acadêmicos a aproximação e a sensibilização para o significado e a necessidade da realização da avaliação institucional. Forneceu ainda subsídios para a disciplina de "Vivência, Observação no CENSE e Síntese", uma vez que os participantes trouxeram conhecimentos inerentes ao histórico da avaliação institucional, à legislação, a funções da avaliação e, previamente, já haviam discutido o sistema de monitoramento e avaliação do SINASE.

A compreensão da avaliação enquanto um processo contínuo, sistemático e de prestação de contas requer que estejamos disponíveis para tal, o que não é uma tarefa fácil. A sensibilização para a importância e a necessidade da avaliação é um processo contínuo, que deve oferecer condições para que os sujeitos envolvidos se apropriem do processo de construção e compreensão das informações, assim como a sua utilização no cotidiano institucional.

No decorrer da disciplina, o processo de sensibilização foi estimulado a partir dos encontros em sala de aula onde os participantes puderam, por meio da exposição de suas ações na instituição, refletir sobre a realidade institucional em sua totalidade e se familiarizarem com a concepção da avaliação enquanto um instrumento de aprimoramento da gestão, da prática profissional individual e coletiva, e da necessidade e importância da adesão dos sujeitos envolvidos no processo avaliativo.

Concomitante a essa sensibilização e para atender a parte operacional dos trabalhos, organizou-se um planejamento das atividades internas e externas que contemplasse a troca de experiências entre as diferentes modalidades do sistema, ou seja, sistema fechado e aberto. A inclusão dos programas em meio aberto no contexto da disciplina se deu a partir do entendimento de que as redes municipal e estadual devem estar integradas na execução das medidas socioeducativas.

Considerando que o grupo era composto por 30 alunos, fez-se necessária a composição de quatro subgrupos de trabalho para a realização das visitas institucionais, de maneira que não houvesse interferência na rotina de trabalho da instituição por ocasião destas. Foi estabelecido ainda, um calendário com dias e horários (matutino e 
vespertino) previamente agendados, observando a disponibilidade dos membros dos grupos e das instituições envolvidas.

Visando instrumentalizar os discentes para a atividade de campo, possibilitou-se a eles uma reflexão acerca do ambiente físico e infraestrutura das unidades de socioeducação, e dos programas que compõem a rede de serviços na área, a partir de suas experiências, da especificidade de trabalho de cada um no sistema socioeducativo ou de garantia de direitos.

Na sequência, refletimos sobre as categorias propostas pelo SINASE: 1. Direitos Humanos, 2. Ambiente físico e infraestrutura, 3. Atendimento socioeducativo e 4. Gestão e Recursos Humanos, e os respectivos indicadores de qualidade dos programas de atendimento socioeducativo para meio aberto (Quadro 1) e fechado (Quadro 1), visando sistematizar um roteiro de avaliação a ser aplicado por ocasião das visitas institucionais.

Nesta perspectiva de divisão de trabalhos, ficou definido que cada grupo elegeria uma categoria e seus respectivos indicadores (meio aberto e fechado), procederia à discussão destas com base nas normativas de estruturação, organização e gestão do CENSE e demais instrumentos legais, e elaboraria um roteiro para subsidiar o processo de "Vivência, Observação no CENSE e Síntese". A definição de uma categoria de observação para cada grupo não significava restringir sua percepção a apenas um aspecto da estrutura e organização institucional, mas sim estimular para:

- a compreensão da dinâmica institucional das unidades de socioeducação e dos programas que compõem a rede de serviços na área, no intuito de vivenciar o contexto social e institucional de atendimento aos adolescentes em conflito com a lei, pelo processo de observação direta da dinâmica institucional e contato com os sujeitos que convivem e atuam no mesmo espaço;

- a apreensão da realidade dos adolescentes que cumprem medidas socioeducativas no contexto institucional local e da incorporação desses adolescentes nas diferentes políticas públicas e sociais, nas diferentes instâncias governamentais e a operacionalização do atendimento inicial, estruturado e qualificado aos egressos; 
- o conhecimento da gestão pedagógica do processo socioeducativo atendimento socioeducativo, gestão dos recursos humanos, gestão do sistema e financiamentos;

- o conhecimento do gerenciamento dos sistemas de informação e segurança.

\section{2- Experimentação do processo avaliativo.}

As vivências/observações foram realizadas durante o mês de junho de 2010, e acompanhadas pelas docentes responsáveis pela disciplina e a coordenação do Curso.

A metodologia adotada para o desenvolvimento da disciplina e em especial na atividade de campo buscou considerar a necessidade de documentar, monitorar, encontrar o significado da ação, por meio da presença do pesquisador no campo para colher os seus dados, anotar os comportamentos, conversas informais e formais e os acontecimentos. Pois, em uma abordagem compreensiva o observador/pesquisador deve estar aberto a receber outros elementos interpretativos que podem surgir no campo.

Sendo assim, a demonstração dos resultados ou a síntese interpretativa foi construída a partir de uma "triangulação", conforme conceito de Denzin (apud MINAYO, 2007), que consiste na combinação e no cruzamento de múltiplos pontos de vista, pelo trabalho conjunto de vários observadores/pesquisadores, de múltiplos informantes e múltiplas técnicas de coleta de dados. Assim, devem-se levar em consideração as palavras, ações, conjunto de inter-relações, grupos, instituições e conjuntura. E, segundo Romeu Gomes (2007), a interpretação deverá conter os seguintes princípios: a) buscar a lógica interna dos fatos, dos relatos e das observações; b) situar os fatos, os relatos e as observações no contexto dos atores; e c) produzir um relato dos fatos em que seus atores neles se reconheçam.

Nessa direção, observou-se que o fato da maioria dos alunos fazerem parte do sistema socioeducativo, a "Vivência, Observação no CENSE e Síntese", constituiu-se em um momento único, uma vez que esse espaço Ihes permitiu, além do olhar avaliativo do contexto institucional desprovido do vínculo de trabalho, por se tratar de uma atividade acadêmica, uma reflexão, um repensar coletivo das possibilidades e limites da ação institucional no contexto da realidade do estado do Paraná e, ainda, a busca de 
encaminhamentos para situações que muitas vezes se tornam entraves no desenvolvimento do trabalho socioeducativo.

Essas reflexões emergiram no momento em que os discentes concluíram a fase de visitas e retornaram para a sala de aula para apresentação, por meio de seminários, das observações inerentes às categorias e indicadores de avaliação observados, constantes do roteiro de avaliação por eles elaborados e sistematizados em relatório.

Vale destacar que nesse momento tornou-se evidente a necessidade da realização sistemática da avaliação institucional, uma vez que o exercício realizado possibilitou a verificação e a comparação entre o planejado/esperado para as instituições socioeducativas, a partir dos documentos legais constituídos, e a realidade observada. Tal fato indica que a avaliação institucional necessita não somente das informações provenientes do sistema de monitoramento para realizar o julgamento da eficiência, eficácia e efetividade dos programas socioeducacionais, mas também da avaliação diagnóstica que permite identificar se os padrões de qualidade correspondem ao desejado e subsidiar a gestão.

\section{3- Síntese do processo de vivência e observação.}

$\mathrm{Na}$ perspectiva do SINASE, o monitoramento e avaliação se constituem em importante ação capaz de fornecer subsídios para as unidades e/ou programas de atendimento socioeducativo, quer seja para aquelas de atendimento inicial, internação provisória ou para aquelas de aplicação de medidas socioeducativas. A efetivação desse processo de monitoramento e avaliação pressupõe:

1) estrutura adequada e organizada com recursos humanos especializados e exclusivos para a realização e gerenciamento de estudos e pesquisas necessários para o monitoramento e avaliação do Sistema Nacional de Atendimento Socioeducativo (SINASE);

2) adesão à proposta de monitoramento e avaliação como condição fundamental para a garantia de fidedignidade das informações e para a utilização pedagógica dos dados gerados na alteração da qualidade dos programas de atendimento socioeducativo;

3) definição clara dos responsáveis pelas respostas e tomadas de decisões de mudança em cada nível de ação;

4) capacitação de agentes e operadores bem como a garantia da provisão de recursos para sua implementação nos órgãos geradores de informação;

5) sistema de políticas e programas articulado e pactuado em âmbito nacional, respeitadas as peculiaridades regionais e locais (BRASIL, 2006b, p. 77). 
Ao envolver trabalhadores e gestores da área socioeducativa em um curso de especialização em "Gestão de Centros de Socioeducação", abre-se espaço para a efetivação do processo de monitoramento e avaliação, uma vez que permite a esses a observação, a reflexão e a discussão da realidade institucional que nem sempre é possível de se realizar no cotidiano da ação, no espaço institucional.

A proposição da disciplina "Vivência, Observação no CENSE e Síntese", possibilitou aos discentes um exercício de vivência da realidade do trabalho socioeducativo nas diferentes instituições/programas, observar com maior propriedade as diferentes modalidades de atendimento ao adolescente, tendo por referência os indicadores de qualidade dos serviços prestados, como também as normativas constantes em diferentes documentos de garantia de direitos voltados à criança e ao adolescente e, especificamente, as de natureza pedagógica de medida socioeducativa como já pontuado anteriormente.

Na primeira etapa da disciplina, que envolveu a elaboração do roteiro de visitas e de observação, foi possível aos discentes o levantamento de dados e situações relativas ao funcionamento e ao atendimento do adolescente no espaço institucional, os quais fomentaram e subsidiaram as discussões quanto à importância da realização da avaliação institucional, bem como da construção de um instrumento que agregasse aos indicadores do SINASE outros aspectos, ou seja, buscasse um maior detalhamento dos indicadores a partir da observância das leis e normativas que fundamentam as ações nos regimes socioeducativos.

Em decorrência disso, e com base nas observações coletadas, os grupos de trabalho foram reorganizados de modo que cada grupo reconstruído tivesse em mãos uma das categorias, totalizando o conjunto dessas para cada modalidade de atendimento (meio aberto e fechado). A partir daí foi construído um instrumento de avaliação para cada modalidade de atendimento sendo este apresentado e debatido no conjunto dos participantes. Neste processo, observamos algumas situações que exigiram respostas simples como "sim" ou "não", passíveis de comentários complementares.

Repensando a estruturação desse material, procuramos construir um instrumento que pudesse ampliar os indicadores das respectivas categorias, o detalhamento de 
mensuração da qualidade dos programas de atendimento socioeducativo e a definição de uma escala de avaliação que, de acordo com Ilza Sant'Anna (2002, p. 112), "são construídas por um conjunto de características ou atributos a serem julgados e por algum tipo de escala para indicar o grau em que a característica ou atributo é avaliado".

O SINASE apresenta um detalhamento de indicadores no que diz respeito à estrutura física e suas normativas como condição fundamental para as entidades e/ou programas que executam internação provisória e medidas socioeducativas (Quadro 3). Nas demais categorias/indicadores, estes são apresentados de maneira ampla, sem menção a uma pontuação ou valoração, visando uma avaliação qualiquantitativa.

Assim, o processo de elaboração do instrumento de avaliação buscou detalhar os indicadores para cada categoria proposta pelo SINASE e a construção de uma escala de valoração, com uma base referencial numérica a ser observada e registrada no momento da avaliação, e para alguns indicadores deixou a possibilidade de registro de outras informações. A proposta de instrumento elaborada procurou contemplar todas as categorias/indicadores, envolvendo o meio aberto e o meio fechado.

Dada a extensão da proposta de instrumento elaborada, apresentamos abaixo, a título de exemplificação do exposto, alguns recortes do instrumento, com um exemplo de indicadores para cada uma das quatro categorias e modalidades de atendimento (Quadros 5 e 6), antecedidos pela legenda que serviu como base referencial numérica a ser considerada na avaliação (Quadro 4).

Quadro 4 - Base referencial numérica a ser observada e registrada no momento da avaliação

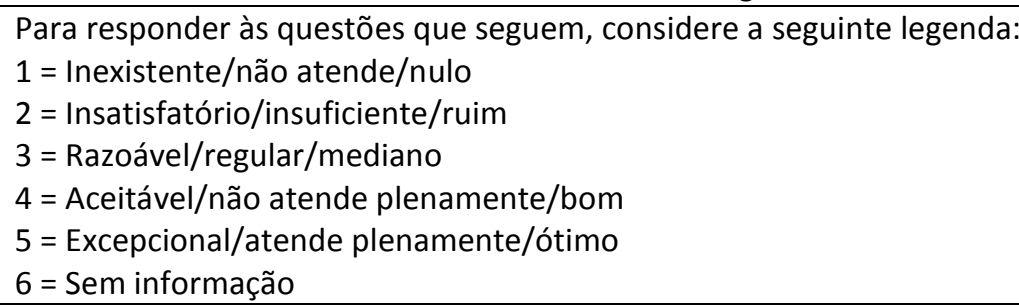

Fonte: Critérios elaborados/organizados pelas autoras, para fins didáticos. 
Quadro 5 - Indicadores de avaliação de unidades de socioeducação - meio aberto (Liberdade Assistida e Prestação de Serviços à Comunidade)

\begin{tabular}{|c|c|c|c|c|c|c|}
\hline \multicolumn{7}{|c|}{ 1. Direitos Humanos nas Unidades de meio aberto } \\
\hline Esporte & 1 & 2 & 3 & 4 & 5 & 6 \\
\hline \multicolumn{7}{|l|}{ Atividades esportivas em diversas modalidades } \\
\hline \multicolumn{7}{|l|}{ Atividades esportivas de caráter pedagógico } \\
\hline \multicolumn{7}{|l|}{ Atividades esportivas com caráter de saúde } \\
\hline \multicolumn{7}{|l|}{ Atividades esportivas internas } \\
\hline \multicolumn{7}{|l|}{ Atividades esportivas externas } \\
\hline \multicolumn{7}{|l|}{ Frequência das atividades esportivas } \\
\hline \multicolumn{7}{|c|}{ 2. Capacidade física e estrutura física nas Unidades de meio aberto } \\
\hline Sala multiuso & 1 & 2 & 3 & 4 & 5 & 6 \\
\hline \multicolumn{7}{|l|}{ Espaço - 25,0 m² } \\
\hline \multicolumn{7}{|l|}{ Iluminação } \\
\hline \multicolumn{7}{|l|}{ Ventilação } \\
\hline \multicolumn{7}{|l|}{ Bancadas de uso geral } \\
\hline \multicolumn{7}{|l|}{ Mesa } \\
\hline \multicolumn{7}{|l|}{ Cadeira } \\
\hline \multicolumn{7}{|l|}{ Armários com segurança } \\
\hline \multicolumn{7}{|l|}{ Arquivo } \\
\hline \multicolumn{7}{|l|}{ Quadro de giz } \\
\hline \multicolumn{7}{|l|}{ Pia } \\
\hline \multicolumn{7}{|l|}{ Outros } \\
\hline \multicolumn{7}{|c|}{ 3. Atendimento Socioeducativo nas Unidades de meio aberto } \\
\hline Atendimento técnico & 1 & 2 & 3 & 4 & 5 & 6 \\
\hline \multicolumn{7}{|c|}{ Fortalecimento de vínculos entre a família e o adolescente } \\
\hline \multicolumn{7}{|l|}{ Encaminhamento para a rede socioassistencial } \\
\hline \multicolumn{7}{|l|}{ Frequência dos atendimentos } \\
\hline \multicolumn{7}{|l|}{ Acesso a toda a equipe técnica } \\
\hline A equipe técnica atende demanda & & & & & & \\
\hline Atendimento psicossocial individual & & & & & & \\
\hline Atendimento psicossocial com frequência reg & & & & & & \\
\hline Quadro de técnicos completos de acordo com & & & & & & \\
\hline Capacitação de acordo com as necessidades & & & & & & \\
\hline 4. Gestão de recursos humanos nas Unidades & & & & & & \\
\hline Capacidade de gestão de recursos humanos & 1 & 2 & 3 & 4 & 5 & 6 \\
\hline Regimento Interno & & & & & & \\
\hline Acesso ao Regimento Interno & & & & & & \\
\hline Plano de cargos e salários próprio & & & & & & \\
\hline Descrição de cargos e funções & & & & & & \\
\hline Programa de saúde ocupacional (PSO) & & & & & & \\
\hline Organograma & & & & & & \\
\hline Fluxo de informação e comunicação & & & & & & \\
\hline Servidores do quadro próprio & & & & & & \\
\hline Servidores terceirizados & & & & & & \\
\hline
\end{tabular}

Fonte: Dados coletados e organizados pelos discentes e docentes da disciplina "Vivência, Observação no CENSE e Síntese", nas Unidades/Programas de Socioeducação de Londrina, conforme categorias de avaliação do SINASE. 
Quadro 6 - Indicadores de avaliação de unidades de socioeducação - meio fechado (internação, internação provisória e semiliberdade)

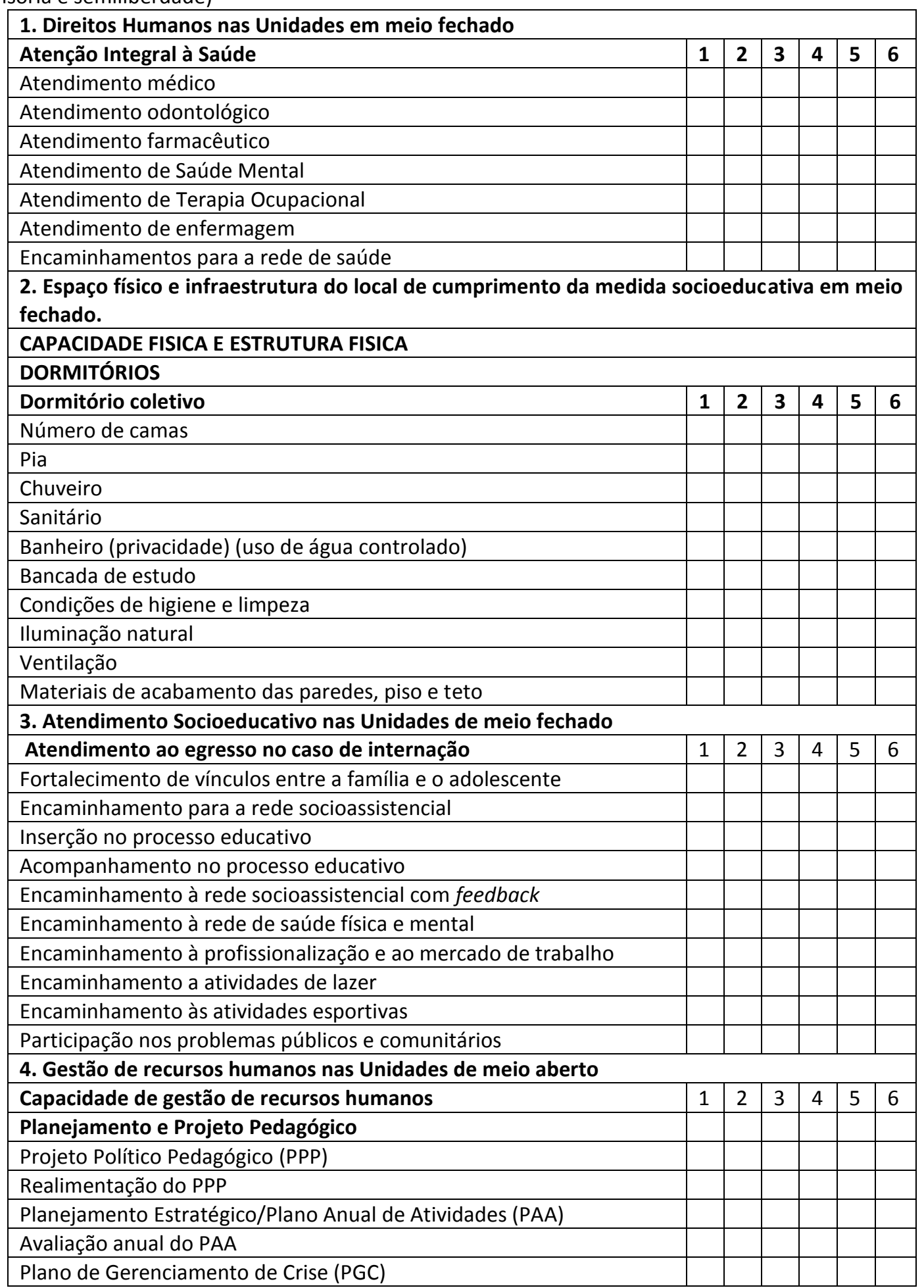

Fonte: Dados coletados e organizados pelos discentes e docentes da disciplina "Vivência, Observação no CENSE e Síntese", nas Unidades/Programas de Socioeducação de Londrina, conforme categorias de avaliação do SINASE.

Vale destacar que um dos momentos da disciplina envolvia a aplicação do instrumento de avaliação (pré-teste) nas unidades visitadas, mas em razão do limite de 
tempo a ação não foi realizada. $O$ instrumento chegou a ser utilizado pelos alunos que realizaram visita às unidades de socioeducação, à Fundação Criança de São Bernardo do Campo e à Fundação Casa de Sorocaba, ambas no estado de São Paulo.

Embora a disciplina não tivesse como foco principal, a avaliação das instituições de socioeducação, e sim a construção de instrumento de avaliação, evidenciaram-se no processo de síntese alguns pontos relevantes que suscitaram novas reflexões e que, de certo modo, podem interferir na eficiência e eficácia do trabalho socioeducativo. Essas reflexões estavam relacionadas, em parte, à gestão de recursos humanos e direitos humanos.

A vivência desses sujeitos, como profissionais inseridos nessas instituições, acrescidas das observações realizadas e das discussões coletivas em sala, apontaram para: a dificuldade de reposição do quadro de pessoal, dada a ausência de concurso público, fato este que dificulta a expansão do trabalho socioeducativo junto aos adolescentes; a necessidade de elaboração pelo Estado de um plano de cargos e salários; a não participação do funcionário em seu processo avaliativo, bem como no feedback deste; a necessidade de maior conhecimento dos funcionários sobre o regimento das unidades de socioeducação; a necessidade de um plano de saúde ocupacional para os funcionários, levando-se em consideração o estresse do ambiente de trabalho; e a dificuldade de gestão em função da própria burocracia do Estado (infraestrutura; aquisição de materiais de naturezas diversas, entre outras).

Outra questão que suscitou debates estava relacionada à categoria de Direitos Humanos. De modo geral, os participantes foram unânimes na observação quanto ao atendimento aos pressupostos normativos e legais, contudo ressaltaram o rigor da rotina e procedimentos adotados no momento do ingresso do adolescente no sistema, como, por exemplo, o modo de circular no espaço institucional e especialmente o corte de cabelo adotado. Embora essa questão seja discutida dentro do sistema, a prática de raspar o cabelo é respaldada e fundamentada no argumento da higiene e da segurança. Em contraposição, nas instituições externas ora visitadas, observou-se que tal procedimento também é adotado, porém, é passível de mudança à medida que o adolescente conquista uma progressão positiva no sistema de socioeducação. 
A obrigatoriedade de raspar o cabelo dos adolescentes internados, sob o pretexto de "manutenção da ordem, da disciplina e da higiene" é considerada por alguns juristas e defensores dos direitos humanos como um procedimento que marca o adolescente física e psicologicamente, que remonta às práticas com resquícios de autoritarismo contrários à proposta que privilegia a humanização do atendimento contida no ECA. A raspagem do cabelo é uma prática de constrangimento e abuso de poder, expondo a condição do adolescente à sociedade, "punindo-o além dos limites da lei e dos princípios democráticos de Direito", que "viola a integridade física, psíquica e moral dos adolescentes porque implica em fazê-los aceitar, mesmo que contra a vontade, a alteração de sua condição física e de sua imagem", nas palavras de um juiz em uma sentença (ALBERNAZ JUNIOR, 2010, p. 1). ${ }^{8}$

Em relação ainda aos Direitos Humanos, outra questão suscitada referia-se aos direitos reprodutivos e sexuais. Apesar de ser um tema polêmico no espaço institucional, existe uma compreensão por parte dos educadores sobre as necessidades sexuais do adolescente, contudo, foi observado que não há infraestrutura que permita receber as visitas íntimas e nem medida legal que garanta esse direito. O direito à visita íntima está previsto no Projeto de Lei já mencionado.

\section{Considerações finais}

No desenvolvimento do Curso de Especialização em Gestão de Centros de Socioeducação, foi possível verificar que o processo de avaliação não pode estar desvinculado dos princípios em que se baseia a proposta pedagógica da socioeducação, contida no SINASE e demais legislações e normativas, na perspectiva de constituir-se em ação formadora dos adolescentes que se encontram submetidos ao cumprimento de medidas socioeducativas.

Nessa direção, o instrumento de avaliação, produto deste trabalho, consubstanciou-se em um exercício, ainda que provisório, e que chama a atenção para os indicadores importantes na avaliação das unidades/programas de socioeducação, que

\footnotetext{
${ }^{8}$ Argumentos do juiz em sentença movida pela Defensoria Pública do Estado de São Paulo, em agosto de 2008, contra a Fundação Casa de Ribeirão Preto - SP (ALBERNAZ JUNIOR, 2010).
} 
podem contribuir para que a ação socioeducativa atenda aos seus pressupostos e, consequentemente, aos direitos dos adolescentes.

A experiência também nos levou a refletir sobre a importância do envolvimento familiar e comunitário no processo avaliativo, assim como o seu acesso à formação e à informação, tendo em vista o princípio da "incompletude institucional", que consiste em não considerar a instituição como único contato e comunicação com todos os setores da sociedade. Tema este que carece de maior aprofundamento.

A conclusão do processo desencadeado pela disciplina "Vivência, Observação no CENSE e Síntese" culminou com a elaboração de proposta de instrumento de "Monitoramento e Avaliação de Qualidade dos Programas de Atendimento Socioeducativo", aqui apresentado parcialmente, a qual foi encaminhada na íntegra para a SECJ, juntamente com o relatório de encerramento do Curso de "Gestão de Centros de Socioeducação" e, posteriormente, apresentada em Seminário sobre o tema, realizado em junho de 2011 na UEL.

\section{Referências}

ALBERNAZ JÚNIOR, V. H. Cabelos raspados à força, nunca mais! Ribeirão Preto, 19 out. 2010. Disponível em:

<http://victorhugoalbernazjr.blogspot.com/search?q=raspar+cabelo>. Acesso em: 17 dez. 2011.

BRASIL. Câmara dos Deputados. Projeto de Lei no 1.627, 2007. Dispõe sobre os sistemas de atendimento socioeducativo. 2007. Disponível em:

<http://www.camara.gov.br/proposicoesWeb/fichadetramitacao?idProposicao=360092>. Acesso em: 17 dez. 2011.

Saraiva, 2005.

. Constituição (1988). Constituição da República Federativa do Brasil. São Paulo:

Estatuto da Criança e do Adolescente. Curitiba: Imprensa Oficial, 2006a.

Presidência da República. Secretaria Especial dos Direitos Humanos. Conselho Nacional dos Direitos da Criança e do Adolescente. Sistema Nacional de Atendimento Socioeducativo - SINASE. Brasília: Secretaria Especial dos Direitos Humanos: CONANDA, 2006b.

CUNHA, C. G. S. Avaliação de políticas públicas e programas governamentais: tendências recentes e experiências no Brasil. 2006. Disponível em:

<http://www.ufpa.br/epdir/images/docs/paper06.pdf>. Acesso em: 17 dez. 2011. 
GADOTTI, M. Avaliação institucional: necessidade e condições para sua realização. Disponível em:

<http://www.paulofreire.org/twiki/.../institucional/.../avalinstitucional.pdf>. Acesso em: 25 out. 2009.

GOMES, R. Trabalho de campo: contexto, interação e descoberta. In: MINAYO, Maria Pesquisa social: teoria, método e criatividade. 25. ed. Petrópolis: Vozes, 2007. p. 61-77.

MINAYO, M. C. S. O desafio do conhecimento: pesquisa qualitativa em saúde. 10. ed. São Paulo: Hucitec, 2007.

PARANÁ. Curso de especialização em gestão de centros de socioeducação. Secretaria de Estado da Criança e da Juventude. Curitiba: SECJ, 2009. Disponível em:

$<$ http://www.escoladegoverno.pr.gov.br/modules/conteudo/print.php?conteudo=416>. Acesso em: 13 dez. 2011.

RODRIGUES, N. Educação: da formação humana à construção do sujeito ético. Educação $e$ Sociedade, São Paulo, v. 22, n. 76, p. 232-257, 2001.

SANT'ANNA, I. M. Por que avaliar? como avaliar? técnicas e instrumentos. 9. ed. Petrópolis: Vozes, 2002.

SARAIVA, J. B. C. Desconstruindo o mito da impunidade: um ensaio de direito (Penal) juvenil. Brasília, 2002. Disponível em: <http://jij.tj.rs.gov.br/jij_site/docs/DOUTRINA/DESCONSTRUINDO+O+MITO+DA+IMPUNI DADE+-+EDITADOB.HTM>. Acesso em: 17 dez. 2011.

VOLPI, M. O adolescente e o ato infracional. 4. ed. São Paulo: Cortez, 2001. 